(1)

George Fox

UNIVERSITY
Digital Commons @ George Fox University

Department of Biomedical, Mechanical, and

Civil Engineering
Faculty Publications - Biomedical, Mechanical, and Civil Engineering

2007

Evaluating Management Decisions to Reduce Environmental Risk of Roadside-Applied Herbicides

Ben D. Giudice

Arash Massoudieh

Thomas M. Young

Follow this and additional works at: https://digitalcommons.georgefox.edu/mece_fac

Part of the Engineering Commons 


\title{
Evaluating Management Decisions to Reduce Environmental Risk of Roadside-Applied Herbicides
}

\author{
Ben D. Giudice, Arash Massoudieh, and Thomas M. Young
}

\begin{abstract}
Management decisions concerning the spraying of herbicides on highway roadsides are evaluated on the basis of their impact on resulting environmental risk. A mathematical transport model was previously applied to the State of California with a Monte Carlo technique, and in this study the results are manipulated to evaluate the risk reduction that results from restricting herbicide application on the basis of site characteristics or changing other application practices. Results show that eliminating herbicide applications where the slope of the grass adjacent to the highway is greater than $30^{\circ}$ has little or no effect on risk. Eliminating application where the width of the grass adjacent to the highway is less than $\mathbf{2} \mathrm{m}$ or where soil organic carbon content is less than $\mathbf{0 . 5 \%}$ can lead to significant reductions in environmental risk for certain herbicides. Additionally, limiting the width of the spray zone and applying the minimum manufacturer-suggested application rate reduce the risk to aquatic ecosystems. Applying at the minimum rate has the greatest potential to decrease risk. Results of this study show that management decisions can have a significant effect on limiting herbicide runoff risks to aquatic ecosystems. Decision makers would have to weigh costs of alternatives to herbicide spraying for controlling roadside vegetation against the environmental risk reductions.
\end{abstract}

Nonpoint source pollution has become a topic of increasing significance in recent years as point source pollution has become more regulated and controlled in the United States. To address nonpoint source pollution, total maximum daily loads (TMDLs) for pollutants of concern have been implemented to meet receiving water quality standards. In some cases, TMDLs have been established for ambient toxicity rather than for a specific pollutant, particularly when the agent of toxicity is unknown. Pesticides have been studied extensively as a prime example of nonpoint source pollution because of their intentional release over wide areas into the environment and potential for disastrous side effects. Models that predict environmental concentrations of pesticides have been widely used to make risk assessments for different applications (1). Most have been in agricultural settings. However, pesticides are used in a wide variety of applications, including roadside vegetation management programs.

Herbicides are applied along highway roadsides by many transportation agencies for safety and maintenance purposes, for exam-

Department of Civil and Environmental Engineering, University of California, Davis, 1 Shields Avenue, Davis, CA 95616. Corresponding author: B. D. Giudice, bdgiudice@ ucdavis.edu. ple, to reduce fire hazards, promote driver visibility, and prevent damage to pavement. Toxicity has been observed experimentally at discharge points of the runoff that transports these herbicides (2). To predict this toxicity, a mathematical model was developed (3) and stochastically employed over a wide span of scenarios generated based on conditions found in California (B. D. Giudice, A. Massoudieh, X. Huang, and T. M. Young, A Stochastic Simulation Procedure for Selecting Herbicides with Minimum Environmental Impact, unpublished paper).

Given the results and in light of ambient toxicity TMDLs, an important question is, Which actions, if any, might be taken to reduce toxicity? Results of the previous simulations can be manipulated to determine the potential environmental benefit of management decisions concerning where, how, and how much herbicide should be applied. This concept was used by Probst et al. to investigate the effects of parameter changes and management decisions such as increased buffer width on pesticide runoff in agricultural applications (4).

The objective of this study is to compare the extent to which various management decisions on spraying herbicides on highway roadsides can reduce environmental risk. The decision-making parameters examined in this study include grass slope, grass width, soil organic carbon (OC) content, application width, and application rate.

\section{METHODS}

The one-dimensional model employed in this study incorporates surface runoff along with infiltration and subsurface flow, and it incorporates a transport component that models herbicide advection, dispersion, partitioning, and decay. Its application is based on the first storm event following application of the herbicide, and models transport from the spray zone to the adjacent receiving water or storm drain, producing an event mean concentration (EMC) as output. This is defined as follows:

$\mathrm{EMC}=\frac{\text { total herbicide loss }}{\text { total runoff volume }}$

Probability distribution functions of the model input parameters were fitted to measured field data to allow for a Monte Carlo simulation of the model across California. Geometric data were gathered from a statewide survey of 25 sites (2). Soil data were gathered from a similar survey of 57 samples from those sites (2). Meteorological data were taken from the National Oceanic and Atmospheric Administration database for three weather stations in northern, central, and southern California (5). Two basic highway geometries were considered. 


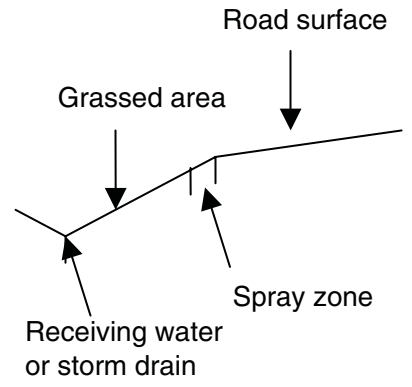

(a)

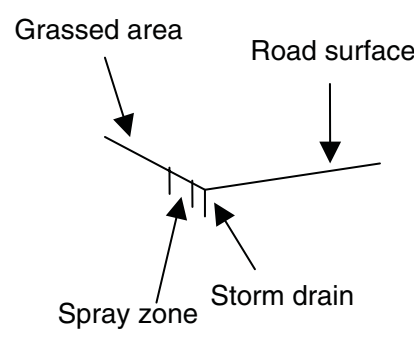

(b)
FIGURE 1 Highway geometry cross-sections showing (a) Type 1 and $(b)$ Type 2. (Source: B. D. Giudice, A. Massoudieh, X. Huang, and T. M. Young. A Stochastic Simulation Procedure for Selecting Herbicides with Minimum Environmental Impact. Unpublished paper.J

Figure 1 illustrates the difference between type 1 (T1) and type 2 (T2) geometries. In-depth detail on the model and stochastic simulation used in this study can be found, respectively, in Massoudieh et al. (3) and the earlier mentioned work of Giudice et al.

Previous work has shown that sorption to soil, especially to the organic matter fraction, is the primary process controlling transport of a wide range of herbicides (6); therefore, 20 herbicides were divided into seven categories on the basis of their approximate OC normalized distribution coefficient, $K_{\mathrm{OC}}$, defined as

$$
K_{\mathrm{OC}}=\frac{C_{\text {soil }}}{C_{\text {water }} \times f_{\mathrm{OC}}}
$$

where

$$
\begin{aligned}
C_{\text {soil }} & =\text { herbicide concentration in soil }(\mathrm{mg} / \mathrm{kg}), \\
C_{\text {water }} & =\text { herbicide concentration in water }(\mathrm{mg} / \mathrm{L}), \text { and } \\
f_{\mathrm{OC}} & =\text { mass fraction of OC in soil }(\mathrm{g} / \mathrm{g}) .
\end{aligned}
$$

Normalizing the soil-water distribution coefficient $\left(K_{d}=C_{\text {soil }} / C_{\text {water }}\right)$ by $\mathrm{OC}$ content has been shown to produce $K_{\mathrm{OC}}$ values that are nearly constant for a particular chemical on a wide range of soils. Herbicide properties are shown in Table 1. Each category was run through the simulation for each combination of meteorological region and highway type.

The simulation consisted of running the model for 10,000 sets of input data generated according to the probability distributions as mentioned for each meteorological region, highway type, and herbicide category. For many cases, little runoff resulted from the particular set of variables in the experiment. Because the concentration could not be realistically calculated for those events, these cases were simply ignored in the final results. The remaining data sets numbered from 355 to 4,825 (B. D. Giudice et al., mentioned earlier).

Results from the stochastic simulation were used to calculate frequencies of potential toxicity (FPT) and average toxicity units (TU). The environmental endpoint for each herbicide was the minimum

\begin{tabular}{|c|c|c|c|c|c|c|c|c|}
\hline Category & Herbicide & $K_{\mathrm{OC}}(\mathrm{L} / \mathrm{kg})^{a}$ & $\log K_{\mathrm{OC}}$ & Ref. & App. Rate $\left(\mathrm{mg} / \mathrm{m}^{2}\right)^{b}$ & $\begin{array}{l}\text { Endpoint } \\
\text { Conc. }(\mathrm{ppb})^{c}\end{array}$ & $\begin{array}{l}\text { Endpoint } \\
\text { Parameter }\end{array}$ & Species $^{c}$ \\
\hline 1 & Dicamba & 2 & 0.30 & 8 & $7.0-224.2$ & 10 & EC50 & Blue-green algae \\
\hline 1 & Chlorsulfuron & 33.5 & 1.53 & 8 & $1.3-15.8$ & 10 & LC50 & Water flea \\
\hline 1 & Bromacil & 34 & 1.53 & 8 & $168-2,692$ & 5.9 & EC50 & Green algae \\
\hline 1 & Triclopyr & 59 & 1.77 & 8 & $112.1-896.6$ & 260 & LC50 & Rainbow trout \\
\hline 2 & Sulfometuron-methyl & 85 & 1.93 & 8 & $5.3-42.1$ & 2.6 & EC50 & Green algae \\
\hline 2 & Simazine & 100 & 2.00 & 8 & $112-448$ & 4.1 & EC10 & Green algae \\
\hline 2 & Halosulfuron-methyl & 115 & 2.06 & 8 & $3.5-7.1$ & 3.6 & EC50 & Green algae \\
\hline 3 & Tebuthiuron & 340 & 2.53 & 8 & $112.1-672.5$ & 49 & EC50 & Green algae \\
\hline 3 & Dichlobenil & 400 & 2.60 & 9 & $440.1-2,200.9$ & 2,700 & EC50 & Green algae \\
\hline 3 & Paclobutrazol & 400 & 2.60 & 10 & $200,000-800,000$ & 16,200 & LC50 & $\begin{array}{l}\text { Grass carp, } \\
\text { white amur }\end{array}$ \\
\hline 4 & Norflurazon & 673 & 2.83 & 10 & $110-882$ & 9.6 & EC50 & Green algae \\
\hline 4 & Diuron & 804 & 2.91 & 8 & $67-1,345$ & 0.37 & EC50 & Algal mat \\
\hline 5 & Dithiopyr & 1,043 & 3.02 & 11 & $57-172$ & 17 & EC50 & Green algae \\
\hline 5 & Oryzalin & 1,390 & 3.14 & 8 & $224.2-672.5$ & 24 & EC50 & Blue-green algae \\
\hline 5 & Oxyfluorfen & 1,500 & 3.18 & 8 & $14.0-224.2$ & 0.676 & EC50 & Green algae \\
\hline 5 & Oxadiazon & 2,300 & 3.36 & 10 & $224.2-448.3$ & 3.4 & EC50 & Diatom \\
\hline 6 & Trifluralin & 9,900 & 4.00 & 8 & $42.0-224.1$ & 7.2 & LC50 & Rainbow trout \\
\hline 6 & Pendimethalin & 11,100 & 4.05 & 8 & $165.0-447.2$ & 2.4 & EC50 & Green algae \\
\hline 7 & Glyphosate & 31,690 & 4.50 & 8 & $28-1,120.8$ & 10 & LC50 & Water flea \\
\hline 7 & Diquat & 100,000 & 5.00 & 8 & $52.3-837$ & 19 & EC50 & Diatom \\
\hline
\end{tabular}
endpoint of the Environmental Protection Agency ECOTOX values for the three standard organism acute toxicity bioassays (algae,

TABLE 1 Herbicide Properties (8-11)

Source: B. D. Giudice, A. Massoudieh, X. Huang, and T. M. Young, A Stochastic Simulation Procedure for Selecting Herbicides with Minimum Environmental Impact, unpublished paper.

${ }^{a}$ Average value of cited range.

${ }^{b}$ All application rates were taken from herbicide labels.

${ }^{c}$ All toxicity data were taken from the Environmental Protection Agency ECOTOX database; $\mathrm{ppb} \approx \mu \mathrm{g} / \mathrm{L}$. 
water flea, and fish). For the purpose of calculating FPT, an event was denoted as toxic if its EMC was greater than the endpoint for the applied herbicide. Parameters are defined as follows:

$$
\begin{aligned}
& \mathrm{FPT}=\frac{\text { number of events with EMC } \geq \text { endpoint }}{\text { number of events }} \times 100 \\
& \mathrm{TU}=\frac{\mathrm{EMC}}{\text { endpoint }}
\end{aligned}
$$

Because of the foregoing elimination of simulations, results should be interpreted as the probability that a storm event that generates measurable runoff will exceed the specified environmental endpoint. It is essential to recognize that FPT and TU are based on EMCs in the roadside drainage ditch or storm drain, but waters containing these herbicides will almost always be diluted on mixing with a larger water body such as a river or lake. Therefore, the concentration that the target organism sees will most likely be far less than from the computed EMC. In addition, the high concentrations may not be sustained for long enough to cause toxic effects. Nevertheless, results provide a conservative concentration in light of the difficulty of characterizing dilution and exposure duration effects on a regional scale (B. D. Giudice et al.). Another important caveat on results is that all simulations assume an edge-of-pavement application over an extended area while not all of the herbicides listed in Table 1 may be used in such applications.

Several modifications to application practices based on site characteristics were considered. The first modification considered eliminating applications for which the grass slope was greater than $30^{\circ}$. The second was eliminating applications for which the grass width was less than $2 \mathrm{~m}$. The third was eliminating applications for which the soil OC was less than $0.5 \%$. Finally, both the second and third modifications were considered simultaneously because these modifications resulted in the greatest effects. The specific cutoff value for modifications 1,2 , and 3 was chosen such that the eliminated portion represented approximately $10 \%$ to $15 \%$ of the sites. The final modification ( 2 and 3 together) resulted in approximately $20 \%$ to $25 \%$ of the sites eliminated. The modified frequency of potential toxicity and average
TUs for each active ingredient, region, and highway type were compared with the unmodified values to obtain projected environmental benefit (or detriment) of the associated management decision.

Application procedure modifications were considered next. As stated in the earlier mentioned work by Giudice et al., application width was $1.36 \mathrm{~m}, 2.04 \mathrm{~m}$, and $2.72 \mathrm{~m}$ in an estimated $70 \%, 25 \%$, and $5 \%$ of the cases, respectively. The first modification was eliminating applications for which the application width was greater than $1.36 \mathrm{~m}$. The next analyses compared manufacturer-suggested application rate minimums to maximums. Because the model is explicitly linear with respect to application rate, results were simply scaled by the appropriate rates and compared. Finally, toxicity targets were established, and application rates required to meet those targets were calculated by computer iteration.

\section{DISCUSSION OF RESULTS}

\section{Site Characteristics}

The grass slope modification had virtually no effect on average TUs observed at the monitoring point. Figure 2 shows results of the analysis for Central California. Similar results were obtained for the two other regions (data not shown). In all cases, reductions were small $(<5 \%)$ or negative, indicating no significant statistical difference between applying at all sites and applying only at those with grass slope $<30^{\circ}(p=0.29-0.97$, average $p=0.60)$. These results suggest that management decisions regulating maximum slope for spraying are unlikely to yield sufficient benefits to warrant implementation.

Grass width and soil OC modifications showed strong potential to reduce average TUs (Figure 3). The impact of these restrictions increased with increasing herbicide $K_{\mathrm{OC}}$ for $\mathrm{T} 1$ geometries and generally followed the same trend for $\mathrm{T} 2$. For $\mathrm{T} 1$, increasing the grass width and soil OC limits the herbicide transport along the entire slope, the effect being greater for herbicides with higher $K_{\mathrm{OC}}$. Therefore, eliminating the cases where grass width or soil OC is exceptionally low results in lower average concentrations and thus toxicity. With the exception of extremely low $K_{\mathrm{OC}}$, the reduction was always greater

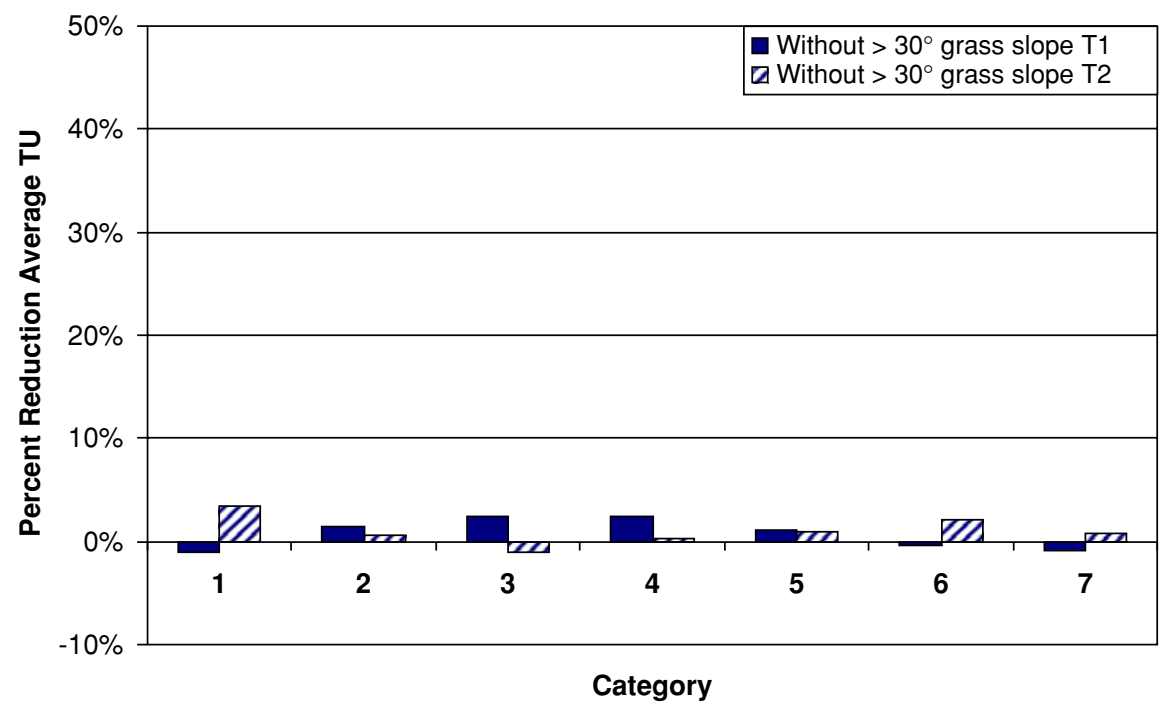

FIGURE 2 Central California TU reduction under grass slope modification for both basic highway geometries and all herbicide categories. 


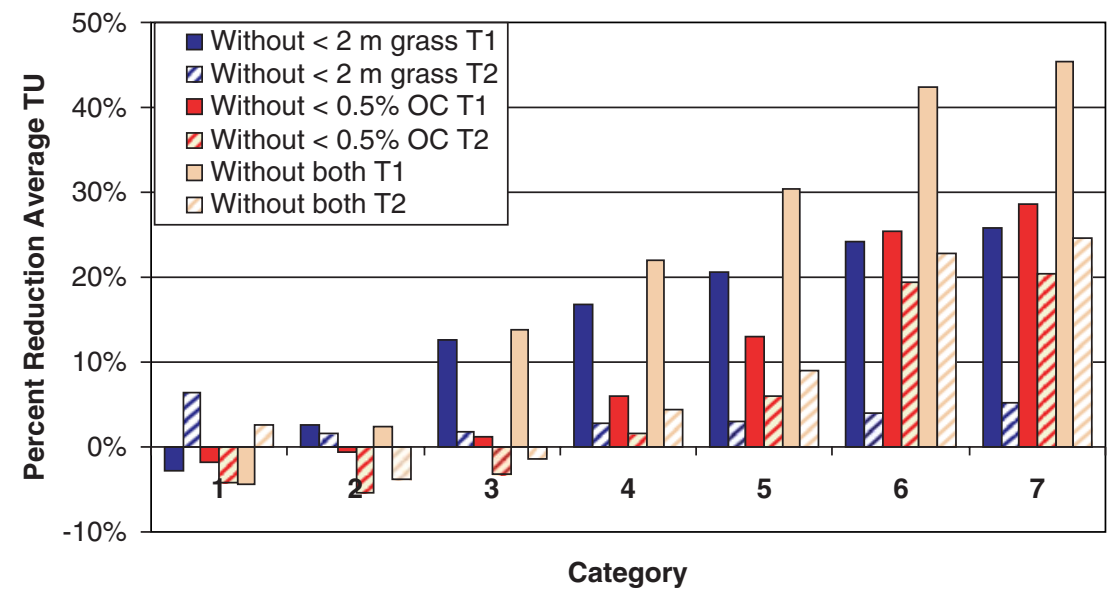

FIGURE 3 Average TU reduction (averaged over all three regions) under grass width and organic carbon modifications for both basic highway geometries and all herbicide categories.

for $\mathrm{T} 1$ geometries than for those in $\mathrm{T} 2$. For T2, the receiving water or storm drain is adjacent to the road; thus, grass width refers to the grass on the opposite side of the receiving water or storm drain. This area serves only to dilute herbicide runoff and not attenuate transport. Eliminating short grass slopes thus increases this dilution effect, driving down average concentrations and thus toxicity. For T2, soil OC has an effect only in the spray zone itself, because the spray zone is adjacent to the storm drain. Because $\mathrm{OC}$ is limiting herbicide transport only in the short spray zone in the T2 configuration, OC changes have less of an effect than in $\mathrm{T} 1$, where it affects transport over the entire grass slope.

Results show that management decisions to avoid spraying when the grass width is less than $2 \mathrm{~m}$ or soil OC is less than $0.5 \%$ should decrease average toxicity in receiving waters for medium to high $K_{\mathrm{OC}}$ herbicides. While it is possible for an applicator to quickly measure or estimate the grass width, the same cannot be said for soil OC. However, an appropriate measure may be to avoid spraying when the spray zone is clearly mostly gravel or sand, although soils with high rock or sand percentage are conducive to infiltration and may exhibit little to no runoff. This technique may not hit the $0.5 \%$ OC mark, but it should have a similar effect to what the results show. It is unlikely that much vegetation will grow in soils with extremely low OC anyway. If vegetation control is essential in these areas, mowing could be employed instead of spraying. If low $K_{\mathrm{OC}}$ herbicides must be applied, these management decisions are of no use, because they show little or no toxicity reduction. Table 2 is a simple reference that summarizes Figure 3 and could be used as a tool by decision makers or applicators to decide whether a site should be sprayed, given its grass width and soil OC.

\section{Application Procedure}

The application width modification resulted in moderate reductions in average TUs (see Figure 4). For T1 geometry, reductions were slightly higher for herbicides with low and high $K_{\mathrm{OC}}$ than for those with moderate $K_{\mathrm{OC}}$, and the average reduction was $16.7 \%$. For T2 highways, reductions were slightly greater for those herbicides with moderate to high $K_{\mathrm{OC}}$ than for those with low or very high $K_{\mathrm{OC}}$, and the average reduction was $8.8 \%$.
Because this modification does not involve avoiding spraying altogether but simply limits the spray area, management decisions to avoid wide application widths entirely may be sufficient in controlling vegetation. However, mowing may need to be implemented to supplement the spraying in some instances. This may be evaluated on a case-by-case basis, though, because reductions are not remarkable.

The management control variable that can have the most significant effect on reducing risk among those considered here is reducing the application rate. If the minimum rate were used instead of the maximum, average TUs decrease by $50 \%$ to $98 \%$, with a median reduction of $85 \%$. While applying at the minimum rate is preferable to applying at the maximum rate, for some herbicides the benefit is minor (e.g., less than 1\% FPT reduction), and for many, the risk may

TABLE 2 Summary of Environmental Benefits for Management Options

\begin{tabular}{llll}
\hline$K_{\text {OC }}{ }^{a}$ & Type & Without Spraying & $\begin{array}{l}\text { Effect on Average } \\
\text { Reduction }\end{array}$ \\
\hline Low & 1 & $<2$ m grass & None \\
Low & 1 & $<0.5 \%$ OC & None \\
Low & 1 & Both & None \\
Low & 2 & $<2$ m grass & None \\
Low & 2 & $<0.5 \%$ OC & None \\
Low & 2 & Both & None \\
Medium & 1 & $<2$ m grass & Moderate \\
Medium & 1 & $<0.5 \%$ OC & Minimal \\
Medium & 1 & Both & Significant \\
Medium & 2 & $<2$ m grass & None \\
Medium & 2 & $<0.5 \%$ OC & None \\
Medium & 2 & Both & None \\
High & 1 & $<2$ m grass & Significant \\
High & 1 & $<0.5 \%$ OC & Significant \\
High & 1 & Both & Strong \\
High & 2 & $<2$ m grass & None \\
High & 2 & $<0.5 \%$ OC & Moderate \\
High & 2 & Both & Significant \\
\hline & & & \\
\hline
\end{tabular}

${ }^{a}$ Low $=$ categories $1-2 ;$ medium $=$ categories $3-5 ;$ high $=$ categories $6-7$. ${ }^{b}$ None $=<5 \%$ reduction; minimal $=5 \%-10 \%$ reduction; moderate $=10 \%-20 \%$ reduction; significant $=20 \%-30 \%$ reduction; strong $=>30 \%$ reduction . 


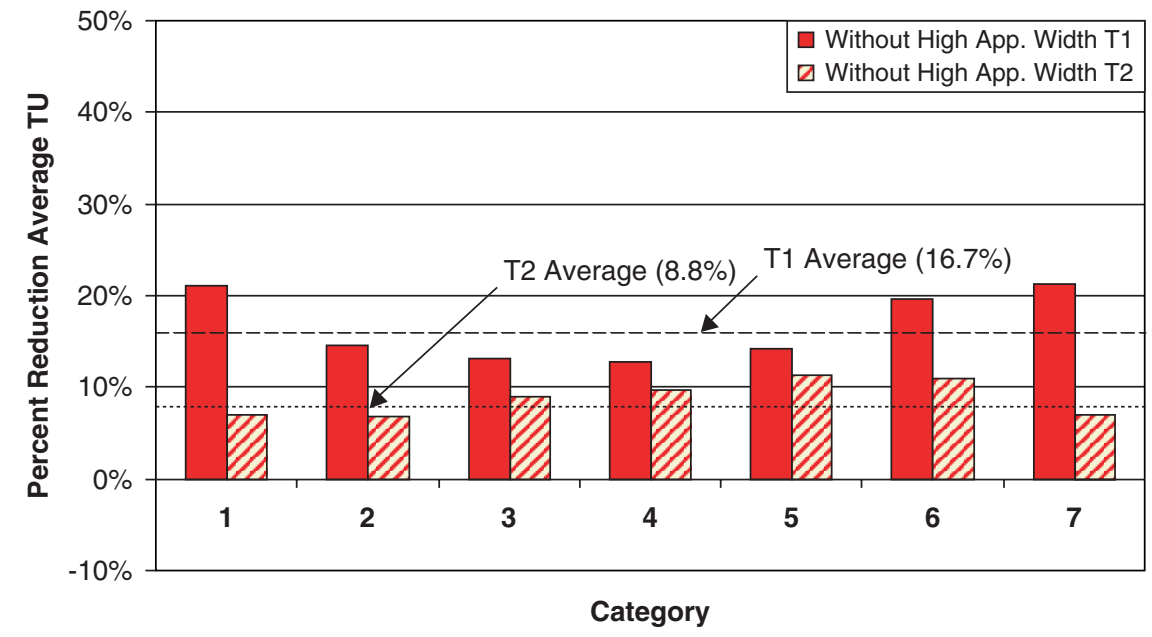

FIGURE 4 Central California TU reduction under application width modifications for both basic highway geometries categories.

still be too high. Establishing an application rate based on environmental targets may be more appropriate. This analysis was conducted for the environmental targets of FPT $=10 \%$ and $50 \%$, as well as $\mathrm{TU}=0.5$ and 1.0 for the worst-case region and highway type. Tables 3 and 4 show results of this analysis in increasing order of the modified rate's percentage of the current maximum rate. The top 10 herbicides are the same in each list, and virtually all require at least an order of magnitude reduction of the current minimum and maximum application rate to meet the target objective. Several require over two orders of magnitude reduction, and Diuron requires over three. Applicators would need to determine if such low application rates render the herbicide totally ineffective. In such cases, a different herbicide should probably be selected.

\section{CONCLUSION}

Herbicide transport parameters and toxicity characteristics directly influence risk to aquatic ecosystems. Understanding the effects of these parameters enables management decisions to limit this risk. This

TABLE 3 AR(FPT10) and AR(FPT50) Versus Current Application Rates

\begin{tabular}{|c|c|c|c|c|c|c|}
\hline Herbicide & $\operatorname{Min}\left(\mathrm{mg} / \mathrm{m}^{2}\right)$ & $\operatorname{Max}\left(\mathrm{mg} / \mathrm{m}^{2}\right)$ & $\operatorname{AR}(\mathrm{FPT} 10)\left(\mathrm{mg} / \mathrm{m}^{2}\right)$ & $\begin{array}{l}\text { AR(FPT10) Percent } \\
\text { of Current Min }\end{array}$ & $\begin{array}{l}\text { AR(FPT50) } \\
\left(\mathrm{mg} / \mathrm{m}^{2}\right)\end{array}$ & $\begin{array}{l}\text { AR(FPT50) Percent } \\
\text { of Current Max }\end{array}$ \\
\hline Diuron & 67 & $1,344.9$ & 0.107 & 0.2 & 0.479 & 0.04 \\
\hline Oxyfluorfen & 14 & 224.2 & 0.245 & 1.8 & 1.11 & 0.5 \\
\hline Simazine & 112.1 & 448.3 & 0.682 & 0.6 & 2.87 & 0.6 \\
\hline Bromacil & 168 & 2,692 & 1.68 & 1.0 & 24 & 0.9 \\
\hline Norflurazon & 110.2 & 882 & 2.75 & 2.5 & 12.4 & 1.4 \\
\hline Paclobutrazol & 200,000 & 800,000 & 2,700 & 1.4 & 11,300 & 1.4 \\
\hline Oxadiazon & 224.2 & 448.3 & 2.5 & 1.1 & 11.5 & 2.6 \\
\hline Pendimethalin & 165 & 447.2 & 3.23 & 2.0 & 15.7 & 3.5 \\
\hline Sulfometuron-methyl & 5.3 & 42.1 & 0.43 & 8.1 & 1.78 & 4.2 \\
\hline Oryzalin & 224.2 & 672.5 & 8.7 & 3.9 & 39.3 & 5.8 \\
\hline Tebuthiuron & 112.1 & 672.5 & 11.8 & 10.5 & 56.4 & 8.4 \\
\hline Dithiopyr & 57 & 172 & 6 & 10.5 & 28 & 16.3 \\
\hline Dicamba & 7 & 224.2 & 2.85 & 40.7 & 41.7 & 18.6 \\
\hline Trifluralin & 42 & 224.1 & 9.68 & 23.0 & 47 & 21.0 \\
\hline Glyphosate & 28 & 1,121 & 55 & $-^{a}$ & 320 & 28.5 \\
\hline Halosulfuron-methyl & 3.5 & 7.1 & 0.59 & 16.9 & 2.48 & 34.9 \\
\hline Diquat & 52.3 & 837 & 110.54 & $-^{a}$ & 609.25 & 72.8 \\
\hline Triclopyr & 112.1 & 896.6 & 74.66 & 66.6 & $1,082.63$ & $-^{a}$ \\
\hline Dichlobenil & 440.1 & $2,200.9$ & 695.33 & $-^{a}$ & $3,298.79$ & $-{ }^{a}$ \\
\hline Chlorsulfuron & 1.3 & 15.8 & 2.88 & $-^{a}$ & 40.75 & $-^{a}$ \\
\hline
\end{tabular}

${ }^{a}$ Calculated rate is higher than manufacturer's listed rate. 
TABLE 4 AR(TU0.5) and AR(TU1.0) Versus Current Application Rates

\begin{tabular}{|c|c|c|c|c|c|c|}
\hline Herbicide & $\operatorname{Min}\left(\mathrm{mg} / \mathrm{m}^{2}\right)$ & $\operatorname{Max}\left(\mathrm{mg} / \mathrm{m}^{2}\right)$ & $\mathrm{AR}(\mathrm{TU} 0.5)\left(\mathrm{mg} / \mathrm{m}^{2}\right)$ & $\begin{array}{l}\text { AR10 Percent } \\
\text { of Current Min }\end{array}$ & $\mathrm{AR}(\mathrm{TU} 1.0)\left(\mathrm{mg} / \mathrm{m}^{2}\right)$ & $\begin{array}{l}\text { AR50 Percent } \\
\text { of Current Max }\end{array}$ \\
\hline Diuron & 67 & $1,344.9$ & 0.13 & 0.2 & 0.26 & 0.02 \\
\hline Bromacil & 168 & 2,692 & 2.755 & 1.6 & 5.51 & 0.2 \\
\hline Oxyfluorfen & 14 & 224.2 & 0.3 & 2.1 & 0.6 & 0.3 \\
\hline Simazine & 112.1 & 448.3 & 0.865 & 0.8 & 1.73 & 0.4 \\
\hline Oxadiazon & 224.2 & 448.3 & 1.5 & 0.7 & 3 & 0.7 \\
\hline Norflurazon & 110.2 & 882 & 3.425 & 3.1 & 6.85 & 0.8 \\
\hline Paclobutrazol & 200,000 & 800,000 & $5,346.255$ & 2.7 & $10,692.51$ & 1.3 \\
\hline Pendimethalin & 165 & 447.2 & 3.745 & 2.3 & 7.49 & 1.7 \\
\hline Sulfometuron-methyl & 5.3 & 42.1 & 0.55 & 10.4 & 1.1 & 2.6 \\
\hline Oryzalin & 224.2 & 672.5 & 10.59 & 4.7 & 21.18 & 3.1 \\
\hline Dicamba & 7 & 224.2 & 4.67 & 66.7 & 9.34 & 4.2 \\
\hline Tebuthiuron & 112.1 & 672.5 & 16.17 & 14.4 & 32.34 & 4.8 \\
\hline Dithiopyr & 57 & 172 & 7.5 & 13.2 & 15 & 8.7 \\
\hline Trifluralin & 42 & 224.1 & 11.23 & 26.7 & 22.46 & 10.0 \\
\hline Glyphosate & 28 & 1121 & 69.195 & - & 138.39 & 12.3 \\
\hline Halosulfuron-methyl & 3.5 & 7.1 & 0.76 & 21.7 & 1.52 & 21.4 \\
\hline Triclopyr & 112.1 & 896.6 & 121.365 & $-^{a}$ & 242.73 & 27.1 \\
\hline Diquat & 52.3 & 837 & 131.47 & $-{ }^{a}$ & 262.94 & 31.4 \\
\hline Chlorsulfuron & 1.3 & 15.8 & 4.67 & $-^{a}$ & 9.34 & 59.1 \\
\hline Dichlobenil & 440.1 & $2,200.9$ & 891.04 & $-^{a}$ & $1,782.08$ & 81.0 \\
\hline
\end{tabular}

${ }^{a}$ Calculated rate is higher than manufacturer's listed rate.

analysis showed that management decisions to avoid spraying due to steep grass slope would result in no significant benefit to aquatic ecosystems. However, similar decisions on narrow grass width or low soil OC (or both) would result in significant reductions to risk for herbicides with moderate to high retention in soils (indicated by high $K_{\mathrm{OC}}$ ). Limiting application width to lower values would result in moderate reductions to risk, whereas applying the manufacturer's suggested minimum rate rather than the maximum rate would almost always result in significant reductions to environmental risk.

\section{ACKNOWLEDGMENTS}

This research has been funded by the National Institute of Environmental Health Sciences and the California Department of Transportation (Caltrans).

\section{REFERENCES}

1. Peterson, R. K. D., and A. N. G. Hulting. A Comparative Ecological Risk Assessment for Herbicides Used on Spring Wheat: The Effect of Glyphosate When Used Within a Glyphosate-Tolerant Wheat System. Weed Science, Vol. 52, 2004, pp. 834-844.

2. Huang, X., S. Fong, L. Deanovic, and T. M. Young. Toxicity of Herbicides in Highway Runoff. Environmental Toxicology and Chemistry, Vol. 24, 2005, pp. 2336-2340.
3. Massoudieh, A., X. Huang, T. M. Young, and M. A. Marino. Modeling Fate and Transport of Roadside-Applied Herbicides. Journal of Environmental Engineering, Vol. 131, 2005, pp. 1057-1067.

4. Probst, M., N. Berenzen, A. Lentzen-Godding, and R. Schulz. ScenarioBased Simulation of Runoff-Related Pesticide Entries into Small Streams on a Landscape Level. Ecotoxicology and Environmental Safety, Vol. 62, 2005, pp. 145-159.

5. Forecast Systems Laboratory and National Climatic Data Center. U.S. Hourly Precipitation Data (CD-ROM), Boulder, Colo., and Asheville, N.C., 1999.

6. Huang, X., T. Pedersen, M. Fischer, R. White, and T. M. Young. Herbicide Runoff Along Highways. 1. Field Observations. Environmental Science and Technology, Vol. 38, 2004, pp. 3263-3271.

7. Tomlin, C., and British Crop Protection Council. The Pesticide Manual: A World Compendium. British Crop Protection Publications, Farnham, United Kingdom, 1997.

8. Vogue, P. A., E. A. Kerle, and J. J. Jenkins. OSU Extension Pesticide Properties Database, 1994. ace.orst.edu/info/npic/ppdmove.htm. Accessed Feb. 3, 2006.

9. Roberts, T. R., D. H. Hutson, and Royal Society of Chemistry (Great Britain). Information Services. Metabolic Pathways of Agrochemicals. Royal Society of Chemistry, Cambridge, United Kingdom, 1998.

10. Pesticide Action Network North America. PAN Pesticides Database. 2006. www.pesticideinfo.org/Detail_Chemical.jsp?Rec_Id=PC33367. Accessed Sept. 2005.

The contents of this paper are solely the responsibility of the authors and do not necessarily represent the official views of NIEHS or Caltrans.

The Roadside Maintenance Operations Committee sponsored publication of this paper. 